\title{
Normal mode Rossby waves and their effects on chemical composition in the late summer stratosphere
}

\author{
D. Pendlebury ${ }^{1}$, T. G. Shepherd ${ }^{1}$, M. Pritchard ${ }^{1,2}$, and C. McLandress ${ }^{1}$ \\ ${ }^{1}$ University of Toronto, Toronto, Canada \\ ${ }^{2}$ now at: University of California, San Diego, USA \\ Received: 5 July 2007 - Published in Atmos. Chem. Phys. Discuss.: 14 August 2007 \\ Revised: 25 January 2008 - Accepted: 3 March 2008 - Published: 3 April 2008
}

\begin{abstract}
During past MANTRA campaigns, ground-based measurements of several long-lived chemical species have revealed quasi-periodic fluctuations on time scales of several days. These fluctuations could confound efforts to detect long-term trends from MANTRA, and need to be understood and accounted for. Using the Canadian Middle Atmosphere Model, we investigate the role of dynamical variability in the late summer stratosphere due to normal mode Rossby waves and the impact of this variability on fluctuations in chemical species. Zonal wavenumber 1, westward travelling waves are considered with average periods of 5, 10 and 16 days. Time-lagged correlations between the temperature and nitrous oxide, methane and ozone fields are calculated in order to assess the possible impact of these waves on the chemical species. Using Fourier-wavelet decomposition and correlating the fluctuations between the temperature and chemical fields, we determine that variations in the chemical species are well-correlated with the 5- and 10-day waves between 30 and $60 \mathrm{~km}$, although the nature of the correlations depend strongly on altitude. Interannual variability of the waves is also examined.
\end{abstract}

\section{Introduction}

The Middle Atmosphere Nitrogen TRend Assessment (MANTRA) campaign measures stratospheric chemical species relevant to ozone depletion from balloon-borne instruments during late summer over Vanscoy, Saskatchewan $\left(52^{\circ} \mathrm{N}, 253^{\circ} \mathrm{E}\right)$ from 10 to $50 \mathrm{~km}$. In order to keep the balloon within the telemetry range for a full day of measurements, the timing of the balloon launch is set to coincide with the turnaround of the stratospheric zonal-mean zonal winds

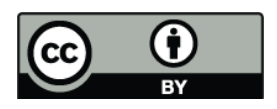

Correspondence to: D. Pendlebury (diane@atmosp.physics.utoronto.ca) from summer easterlies to winter westerlies. While quasistationary planetary waves, which are the largest source of large-scale variability in the Northern Hemisphere stratosphere, are filtered out by the background wind during the summer, some large-scale variability nevertheless exists due to other planetary waves. This variability has an impact on chemical species, and is therefore important to characterize, in order to assess the representativeness of the measurements and isolate long-term trends.

One source of large-scale variability in the atmosphere is normal mode Rossby waves, which are planetary-scale oscillations of the atmosphere. Their spatial structure and phase speeds are determined by the resonance properties of the atmosphere, rather than by forcing mechanisms, making them candidates for large-scale variability in the otherwise quiescent summer stratosphere. The westward travelling 5-day, 10-day and 16-day waves correspond to the first three gravest, latitudinally anti-symmetric modes with zonal wavenumber 1 (e.g. Salby, 1981; Hirooka and Hirota, 1989). This paper will focus on the large-scale variability associated with these modes.

The 5-day wave is a westward travelling disturbance with a period between 4.4 and 5.7 days. It was first observed by Madden and Julian (1972) in ground-based pressure observations, and later by Prata (1989) in Nimbus-6 satellite data. Observations of the 5-day wave compare well with the gravest anti-symmetric wavenumber 1 westward travelling Rossby normal mode (Salby, 1981), with peak amplitudes at $50^{\circ} \mathrm{N}$ and $50^{\circ} \mathrm{S}$. Amplitudes grow with height to a maximum near $70-80 \mathrm{~km}$, and are largest in the summer hemisphere during solstice, although they are approximately symmetric across the equator below about $50 \mathrm{~km}$. During equinox, the amplitudes are symmetric about the equator and grow with height. There is also some variation of the wave characteristics with season - the wave propagates more slowly in spring and autumn (Prata, 1989) - but little change in period is expected with changing background winds since the

Published by Copernicus Publications on behalf of the European Geosciences Union. 
propagation speed is fast compared to the background wind speed (Salby, 1981). Excitation mechanisms for the 5-day wave are unknown, but several modelling studies (Geisler and Dickinson, 1976; Hirota and Hirooka, 1983; Miyoshi and Hirooka, 1999, Cheong and Kimura, 1997, 2001) have examined both the behaviour and excitation mechanisms, including interaction with topography and heating due to moist convection.

The 10- and 16-day waves are also wavenumber 1, westward travelling waves. Since their phase speeds are slower than the 5-day wave, their periods are more strongly affected by the background winds. For the 10-day and 16-day waves, periods between 8.3 and 10.6 days, and 11.1 and 20 days, respectively, may be expected (Salby, 1981). In observations, periods from 1-3 weeks have been linked to the 16day wave (Madden, 1978); consequently, the 16 day period is taken to be an average. For both waves, the amplitude also shows more significant seasonal variation than the 5-day wave. During equinox the amplitude is symmetric across the equator, but during solstice the amplitude is much stronger in the winter hemisphere, falling to near zero in the summer hemisphere in the case of the 16-day wave. For both waves, the amplitude maximizes lower in the atmosphere than the 5-day wave, although under equinox conditions, the 16-day wave has a secondary maximum that grows with height.

These normal modes may be expected to have an impact on chemical species in the stratosphere; however, to our knowledge this impact has not previously been considered. Yet this is an important issue for summertime campaigns such as MANTRA since, as noted earlier, large-scale variability in the summer stratosphere is dominated by such waves. To quantify the nature of these normal modes in the stratosphere during late summer, this paper analyses climate simulations from the Canadian Middle Atmosphere Model (CMAM). The CMAM has advantages in this respect over using analysed fields since it extends well above the region of interest, and includes fully interactive chemistry, ensuring that the chemical and dynamical fields are self-consistent. Moreover, the processes that are involved in coupling the dynamical and chemical fields of these normal modes, namely large-scale transport and chemistry, are well described in the model. Section 2 of the paper summarizes the model and analysis method. Section 3 gives a detailed analysis for one late summer period at $52.6^{\circ} \mathrm{N}$, studying both the waves and the correlations between the temperature and chemical fields. Interannual variability of the 5-, 10- and 16- day waves during late summer is then studied in Sect. 4 for 24 years of the run. Finally, the results are discussed in Sect. 5.

\section{Model and analysis}

The Canadian Middle Atmosphere Model (CMAM) is a general circulation model of the troposphere-stratospheremesosphere system with fully interactive chemistry (Bea- gley et al., 1997; de Grandprè et al., 2000). The version of the model used here has a spherical harmonic truncation T32 $\left(\sim 5.6^{\circ} \times 5.6^{\circ}\right.$ latitude-longitude grid $)$ with 50 vertical levels from the ground to $0.0006 \mathrm{mb}(\sim 100 \mathrm{~km})$. Vertical resolution in the stratosphere and mesosphere is approximately $3 \mathrm{~km}$, increasing slightly with altitude. Smallscale orographic gravity waves are parametrized according to McFarlane (1987); non-orographic gravity waves follow the Hines parametrization (see Hines, 1997; McLandress, 1998). This version of the model is the same as that used by Sankey and Shepherd (2003) and Austin et al. (2003).

To be consistent with other MANTRA studies, the CMAM simulation that is used here was done specifically in support of the MANTRA campaigns. Two data sets, both from the same climate simulation, are used; one with high temporal sampling (i.e. every 10 minutes) but sampled only at 16 evenly-spaced longitudes at $52.6^{\circ} \mathrm{N}$ for a single late-summer period, and another with $18 \mathrm{~h}$ sampling for a 24 year period (chemical fields are saved only every 3 days) at all horizontal gridpoints on 5 pressure levels, which will be referred to later as the global data set. We use the first data set to examine the time evolution of the 5-, 10- and 16-day waves over the summer, and to determine the relationship of the waves in the dynamical fields to the chemical fields nitrous oxide $\left(\mathrm{N}_{2} \mathrm{O}\right)$, methane $\left(\mathrm{CH}_{4}\right)$, and ozone $\left(\mathrm{O}_{3}\right)$. The global data set is used to examine the interannual variability of the wave amplitudes in the dynamical fields.

The largest variability in the CMAM data at higher altitudes is the migrating diurnal tide (McLandress, 1997), which can overwhelm other waves in the model data sampled at less than 12 hours. This effect becomes more prominent with increasing height. In order to filter out the tide without removing other waves of interest, waves with periods less than 1.2 days were filtered. Waves with zonal wavenumber greater than 4 were also filtered to remove any smaller-scale variability and noise. The small-scale variability increases with height due to the growth of gravity waves, but below $70 \mathrm{~km}$, this noise is less than $5 \%$ of the temperature variance and less than $20 \%$ of the variance for the chemical fields.

\section{Seasonal variation}

The result of filtering out the waves with short zonal and temporal scales is shown for one pressure level in Figs. 1 and 2. The Hovmoller plots for temperature (Fig. 1) and nitrous oxide (Fig. 2) at $\sim 62 \mathrm{~km}$ altitude for the period 3 August to 12 September clearly show a wavenumber 1 wave with a westward phase propagation. Both methane and ozone exhibit similar behaviour (not shown). Overlaid on these plots are the phase lines for waves with periods of 5 and 10 days. Both figures clearly show a wavenumber 1 disturbance with a period of 5-7 days in mid- to late August (Julian days 220-235). The period then lengthens to $\sim 10$ days by late 


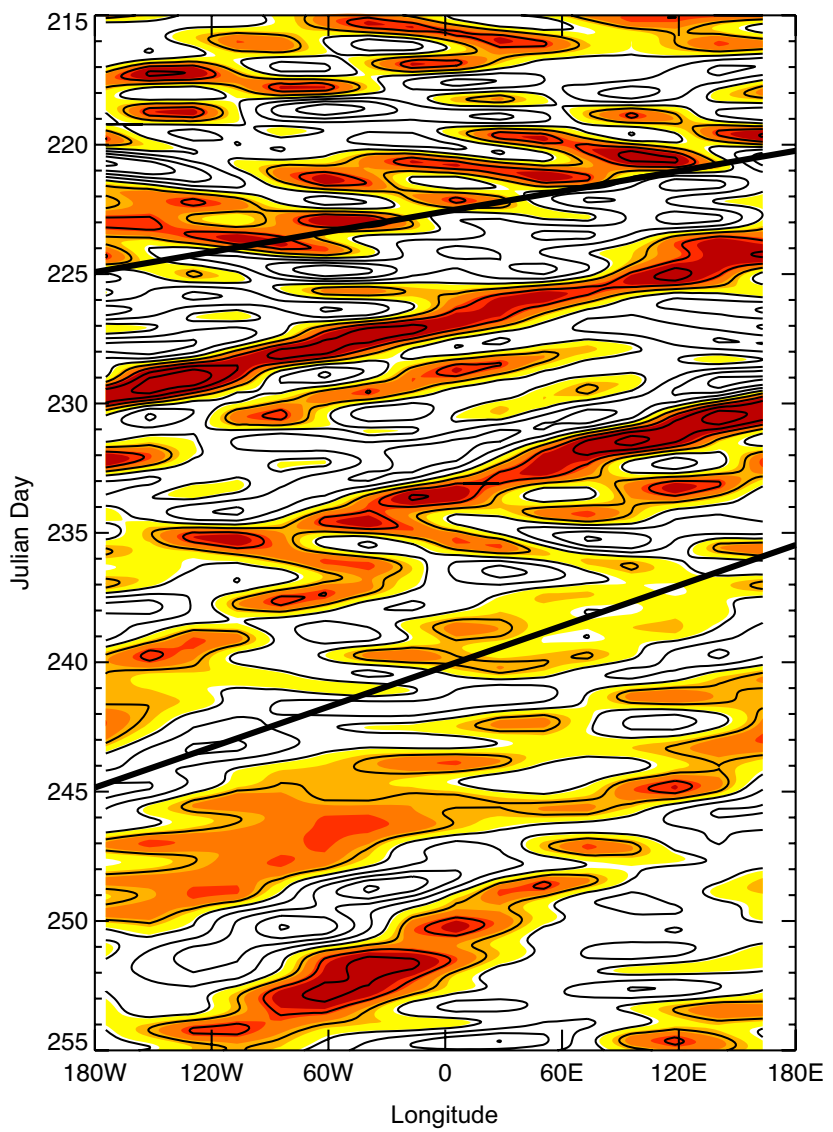

Fig. 1. Hovmoller plot of temperature filtered to retain only waves with periods greater than 1.2 days and zonal wavenumbers less than 5 at $62 \mathrm{~km}$ and $52.6^{\circ} \mathrm{N}$. Contour intervals are $1.2 \mathrm{~K}$ and higher values are shaded. Overlaid are the phase lines for a wave with period 5 days (top) and 10 days (bottom). Julian days range from 215 (3 August) to 255 (12 September).

August to early September (Julian days 240-245), and by mid-September is closer to 16 days for nitrous oxide.

Because of the temporal variation of the wave period, spectral analysis was done using Fourier decomposition in the zonal direction, retaining only wavenumber 1 , and then using wavelet decomposition in time with a Morlet wavelet of order 3. The wavelet analysis is shown in Fig. 3 for all four fields at $62 \mathrm{~km}$. In all fields, waves with periods of approximately 5-7 days are present at the beginning of August (Julian day 215), in agreement with the Hovmoller plots. By mid-September (Julian day 250), the wave in both temperature and ozone has both weakened in amplitude, and lengthened in period to about 7 days, with some power at longer periods. For nitrous oxide and methane, the amplitude has weakened and the period has lengthened to almost 16 days by mid-September.

In order to look at the vertical distribution of the wave amplitudes, the Fourier-wavelet decomposition was integrated

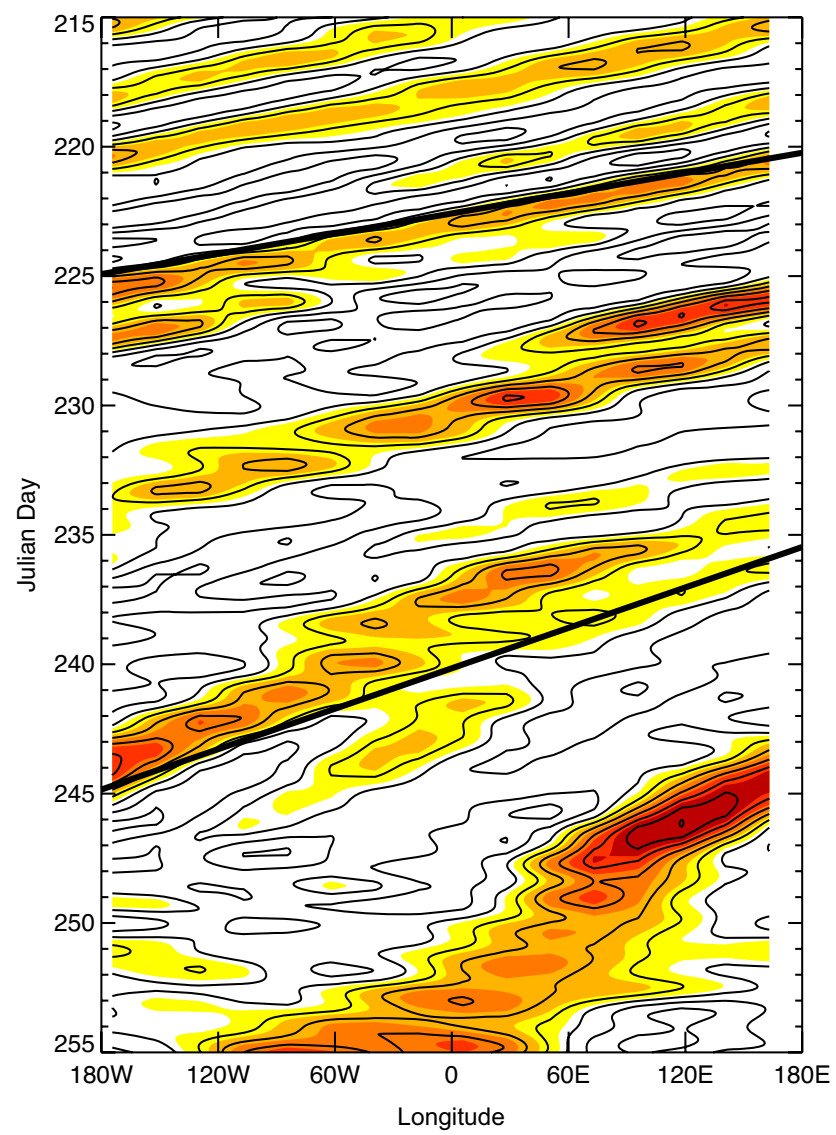

Fig. 2. As for Fig. 1 but for nitrous oxide. Contour intervals are 0.03 ppbv.

over a frequency range for each wave; for the 5-day wave the range was 1.37-0.97 cpd (cycles per day) (periods of 4.6 to 6.5 days), for the 10-day wave $0.68-0.53 \mathrm{cpd}$ (periods of 9.2 to 11.9 days), and for the 16 -day wave $0.44-0.34 \mathrm{cpd}$ (periods of 14.1 to 18.3 days). The results are shown in Fig. 4. In temperature, all three waves have maximum amplitudes between 40 and $50 \mathrm{~km}$ with a secondary maxima above $70 \mathrm{~km}$. Similar behaviour in the wave amplitudes is seen in nitrous oxide and methane below $50 \mathrm{~km}$, although the frequency separation between the three waves is less clear. However, the secondary maxima above $70 \mathrm{~km}$ seen in the temperature is not present in the chemical fields. Because the MANTRA campaign measures at altitudes ranging from $10 \mathrm{~km}$ to $50 \mathrm{~km}$, we will focus on the maxima near $50 \mathrm{~km}$. The 10 - and 16-day waves also develop later in the summer than the 5-day wave.

Some care must be taken in interpreting these results since the wavelet analysis tends to broaden spectral peaks compared to the more common Fourier analysis, so that some signal is evident in the 10-day wave earlier in the summer, although the peak amplitude in Fig. 3 is clearly not at 10 days. In addition, the wave period during early August is somewhat longer than 5 days, adding to the problem of interpreting this 

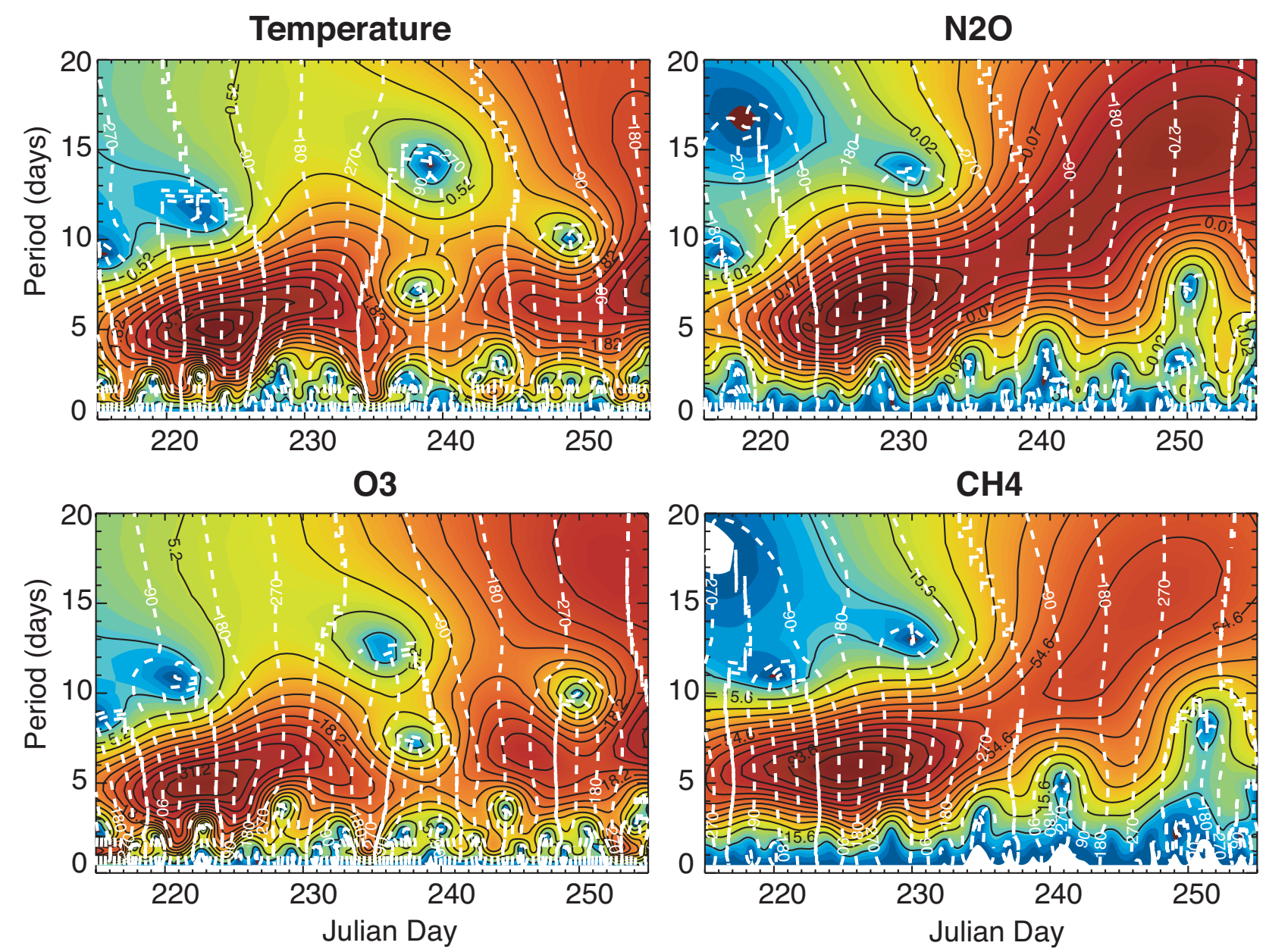

Fig. 3. Fourier-wavelet decomposition for temperature (top-left panel), nitrous oxide (top-right panel), ozone (bottom-left panel) and methane (bottom-right panel) at $62 \mathrm{~km}$ and $52.6^{\circ} \mathrm{N}$. Contour intervals are $0.26 \mathrm{~K} / \mathrm{km} / \mathrm{cpd}$ for temperature, $0.01 \mathrm{ppbv} / \mathrm{km} / \mathrm{cpd}$ for nitrous oxide, $7.8 \mathrm{ppbv} / \mathrm{km} / \mathrm{cpd}$ for methane, and $2.6 \mathrm{ppbv} / \mathrm{km} / \mathrm{cpd}$ for ozone. Phase lines are overlaid on each plot for phases $0,90,180$, and 270 .

as part of the 10-day wave. Furthermore, because the frequency range for the 16-day wave is broad and the evolution of the amplitude between solstice and equinox is similar to that of the 10-day wave, it is sometimes difficult to distinguish between the two.

The zonal-mean zonal wind at $52.6^{\circ} \mathrm{N}$ may provide some explanation for the lengthening of the wave period. Fig. 5 shows the zonal-mean zonal wind evolution over the late summer period. Also shown are the critical lines, where $\bar{u}-c=0$, for westward travelling waves with zonal wavenumber 1 and periods of 5, 10 and 16 days. Rossby waves exhibit westward phase propagation relative to the background flow, so that a wave of a given period may exist only where $\bar{u}>c$, or in the case of the summer easterly jet, where $c$ is more negative than $\bar{u}$. As suggested by Geisler and Dickinson (1976) and Prata (1989) for the 5-day wave, the waves become vertically trapped by the easterly jet. As the zonal-mean zonal wind approaches turnaround, the summer easterly jet is re- duced in magnitude and is squeezed in vertical extent, providing a deeper resonant cavity. As demonstrated in Fig. 5, the area of allowed horizontal propagation (below the critical levels) is largest for the 5-day wave, and smallest for the 16day wave, growing over the season as the jet weakens. Above their critical levels, the waves are expected to be evanescent.

\subsection{Correlations}

Despite the difficulties in interpreting Fig. 4, there is clearly some correlation between the fields for the different waves. The time-lagged correlations for both the spatial fields, and the amplitudes of the 5-day, 10-day and 16-day waves are presented here. Statistical confidence levels were calculated using the method outlined by Sciremammano (1979). This 

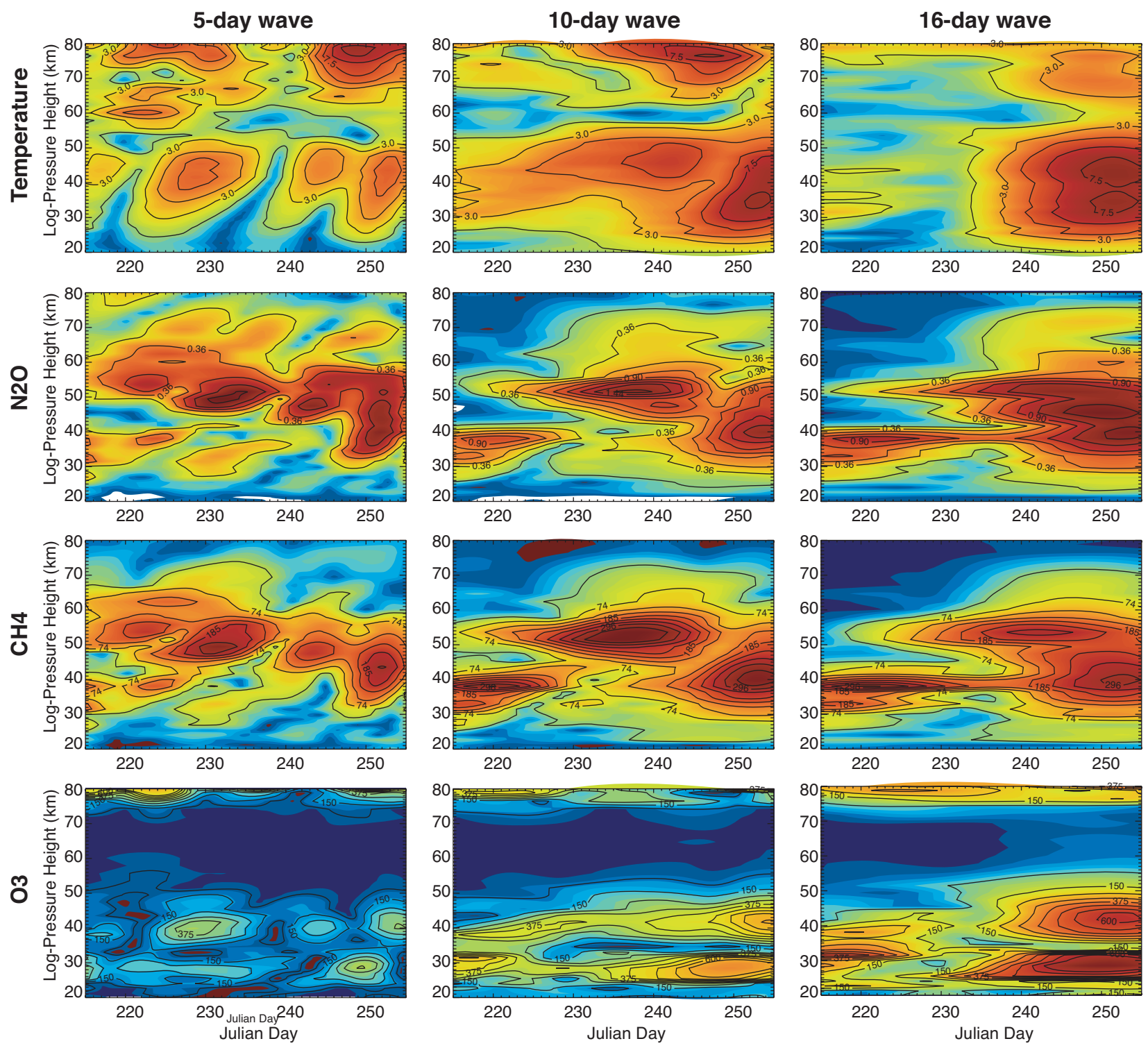

Fig. 4. Fourier-wavelet decomposition showing altitude vs. time for temperature (top row), nitrous oxide (second row), methane (third row), and ozone (bottom row) for the 5-day wave (left column), 10-day wave (middle column) and 16-day wave (right column). Contour intervals are $1.5 \mathrm{~K} / \mathrm{km} / \mathrm{cpd}$ for temperature, $0.18 \mathrm{ppmv} / \mathrm{km} / \mathrm{cpd}$ for nitrous oxide, $37 \mathrm{ppbv} / \mathrm{km} / \mathrm{cpd}$ for methane and $75 \mathrm{ppbv} / \mathrm{km} / \mathrm{cpd}$ for ozone. Nitrous oxide has been scaled by a density factor of $\rho_{0}(1000 \mathrm{mb}) / \rho_{0}(p)$.

method uses a reduced number of degrees of freedom $n$, and the large-lag standard error $\sigma$, calculated from the autocorrelation of each of the two time series, such that the confidence for a given probability level $p$ is

$C_{p}=\sigma\left[\frac{r_{p}^{2}}{1-\frac{1}{n}}\right]^{1 / 2}=\sigma g(n)$

where $|r| \geq r_{p}$ and $r$ depends on the cross-correlation of the two time series; $g(n)$ is calculated numerically. This means that time series with large autocorrelations will give less statistically significant results.
Since both $\mathrm{N}_{2} \mathrm{O}$ and $\mathrm{CH}_{4}$ are long-lived gases with tropospheric sources and middle atmospheric sinks, they are expected to be positively correlated with each other at zero lag, and in fact to exhibit a compact correlation. This is indeed the case with CMAM (see Sankey and Shepherd, 2003). Thus, temperature should exhibit similar correlations with both $\mathrm{N}_{2} \mathrm{O}$ and $\mathrm{CH}_{4}$, and this provides a check on the results below.

Time-lagged correlations of temperature versus nitrous oxide, methane and ozone are shown in Fig. 6. Where the time-lag is positive, the changes in the temperature lead 


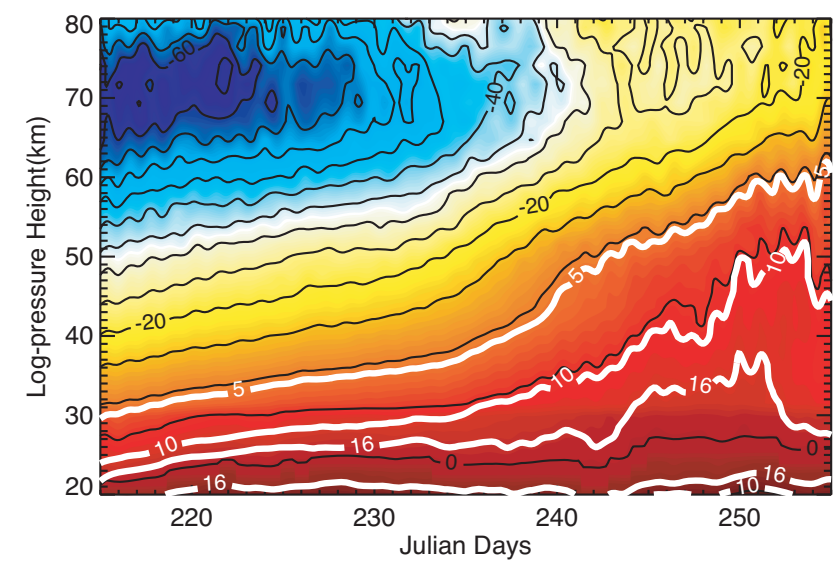

Fig. 5. The zonal-mean zonal wind at $52.6^{\circ} \mathrm{N}$ from 3 August to 12 September. Contour levels are $5 \mathrm{~m} / \mathrm{s}$ and reach a minimum of $-73.3 \mathrm{~m} / \mathrm{s}$. Thick white lines represent the critical lines for planetary waves with zonal wavenumber one and periods of 5, 10 and 16 days, labelled accordingly.

changes in the chemical fields, and where it is negative, the chemical fields lead temperature. However, due to the periodic nature of the 5-, 10- and 16-day waves, causality is not implied by the sign of the lag. No simple relationship is expected. Nitrous oxide and methane are advected on these time scales, so their correlations with temperature will depend on the wave period and on the aspect ratio of the motion (meridional versus vertical). Ozone will be advected in the lower stratosphere, but will respond chemically to temperature perturbations in the upper stratosphere.

Between 28 and $33 \mathrm{~km}$, an increase in temperature corresponds to an increase in nitrous oxide, methane and ozone approximately 2 days later. This corresponds to an altitude region where the chemical lifetimes of these species (months for ozone, several years for methane and nitrous oxide) are longer than transport time scales, and therefore transport is expected to be dominant in controlling the chemical distributions. Further investigation reveals that the correlations in this region are in part due to meridional transport: the nitrous oxide and methane are weakly positively correlated with meridional wind at these heights.

Above $35 \mathrm{~km}$ to about $60 \mathrm{~km}$, where chemical lifetimes are shorter, chemistry becomes more important. Ozone, which has a lifetime of several hours at these altitudes, is anticorrelated with temperature with a zero time-lag, suggesting that it adjusts almost simultaneously to the temperature in this region: an increase in temperature produces a simultaneous decrease in ozone due to an increase in ozone destruction. The role of chemistry should be less important for nitrous oxide and methane, which both have lifetimes of several months at these altitudes. For these species, increases in nitrous oxide and methane lead decreases in temperature, up to 3 days later at $55 \mathrm{~km}$. Presumably transport is also playing a role here.
Time-lagged correlations for the 5-, 10- and 16-day waves as calculated for Fig. 4 are shown in Fig. 7, using both amplitude and phase information. The periodicity of the time series is clearly reflected in the periodic nature of the correlations. Also, because of the longer autocorrelation of the 10- and 16-day wave time series, the significance level of the cross-correlations is reduced. In fact, for the 16-day wave, there are no significant cross-correlations. This is also due in part to the shorter duration of the 16-day wave signal in the data set. However, caution must also be used in interpreting these results. For example, although there appears to be a significant correlation between temperature and nitrous oxide, and between temperature and ozone at $60 \mathrm{~km}$ with a time lag of -1 day, the amplitude of the 10-day wave is very small at this altitude. Therefore, although there may be significant correlations, the 10-day wave may not significantly affect the chemical concentrations in an absolute sense in this region.

What is particularly striking about Fig. 7 is the overall consistency between the different correlation patterns between the 5-, 10,-and 16-day waves, after the lags are scaled by the period of the waves. This suggests that the correlations are intrinsically linked to the waves in a coherent fashion. It also explains why the composite correlations shown in Fig. 6. are not easily explainable: for non-zero lags, the correlations between different waves will tend to cancel (as the lags are different), and any non-zero composite correlations must reflect the dominance of a particular wave. Moreover, the nature of the individual correlations varies with altitude, further complicating the situation. For example, in all three waves there are zero-lag correlations between temperature and ozone at both $40 \mathrm{~km}$ and $60 \mathrm{~km}$, which survive the composite, but nonzero lags around $50 \mathrm{~km}$ (suggesting a more complicated relationship), which do not survive composite.

Focusing on the region between 30 and $60 \mathrm{~km}$ for the 5day wave, an increase in temperature leads an increase in $\mathrm{N}_{2} \mathrm{O}$ and $\mathrm{CH}_{4}$ one day later, and an increase in temperature lags a decrease in $\mathrm{N}_{2} \mathrm{O}$ and $\mathrm{CH}_{4}$ approximately 2-3 days later. For ozone, the simultaneous increase in temperature and decrease in ozone seen in Fig. 7 is present, along with a positive correlation at $\pm 2-3$ days, reflecting the periodicity of the wave. Similar behaviour is seen in the 10-day wave correlations, although with slightly longer lead and lag times (up to 5 days in the case of temperature versus ozone).

Correlations with the waves in the meridional wind field (not shown) suggest that the links between temperature and nitrous oxide, and methane between $30 \mathrm{~km}$ and $60 \mathrm{~km}$ are partly due to meridional transport, although the relationship is complicated and varies with height. Vertical transport may also play a role in determining the relationship between the dynamical and chemical fields, but cannot be tested with this data. The relationship between temperature and ozone for the waves appears to be partly through transport and partly through a chemical balance between temperature and ozone. 

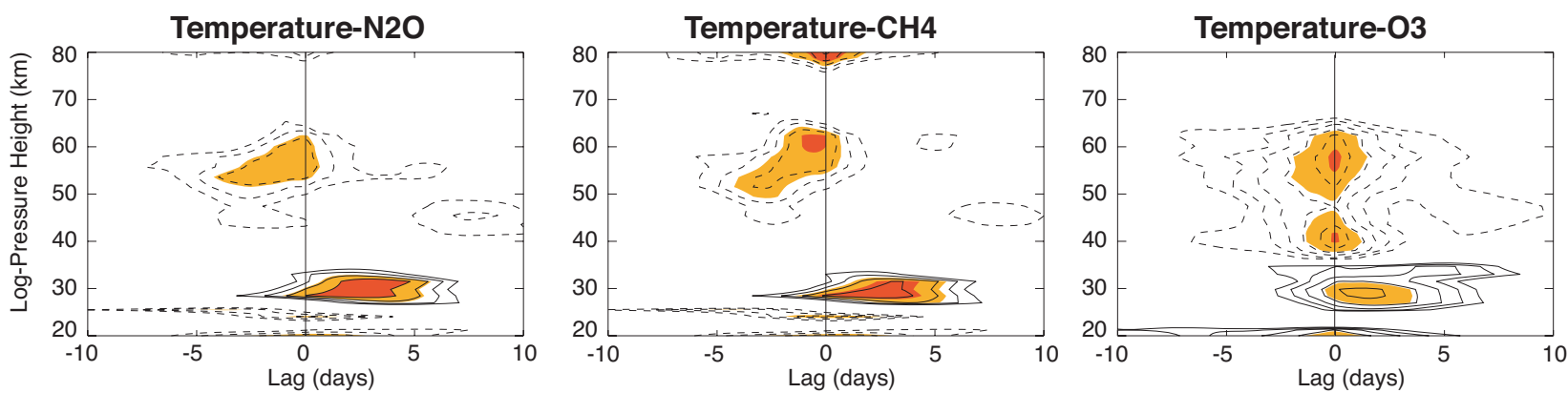

Fig. 6. Time-lagged correlations of temperature and nitrous oxide (left panel), temperature and methane (middle panel), and temperature and ozone (right panel). Contours are 0.05 and are shown only for $\left|\operatorname{Cor}_{X Y}(\tau)\right| \geq 0.5$. Significance levels for the $90 \%$ (yellow), 95\% (orange) and $99 \%$ (red) are shown.
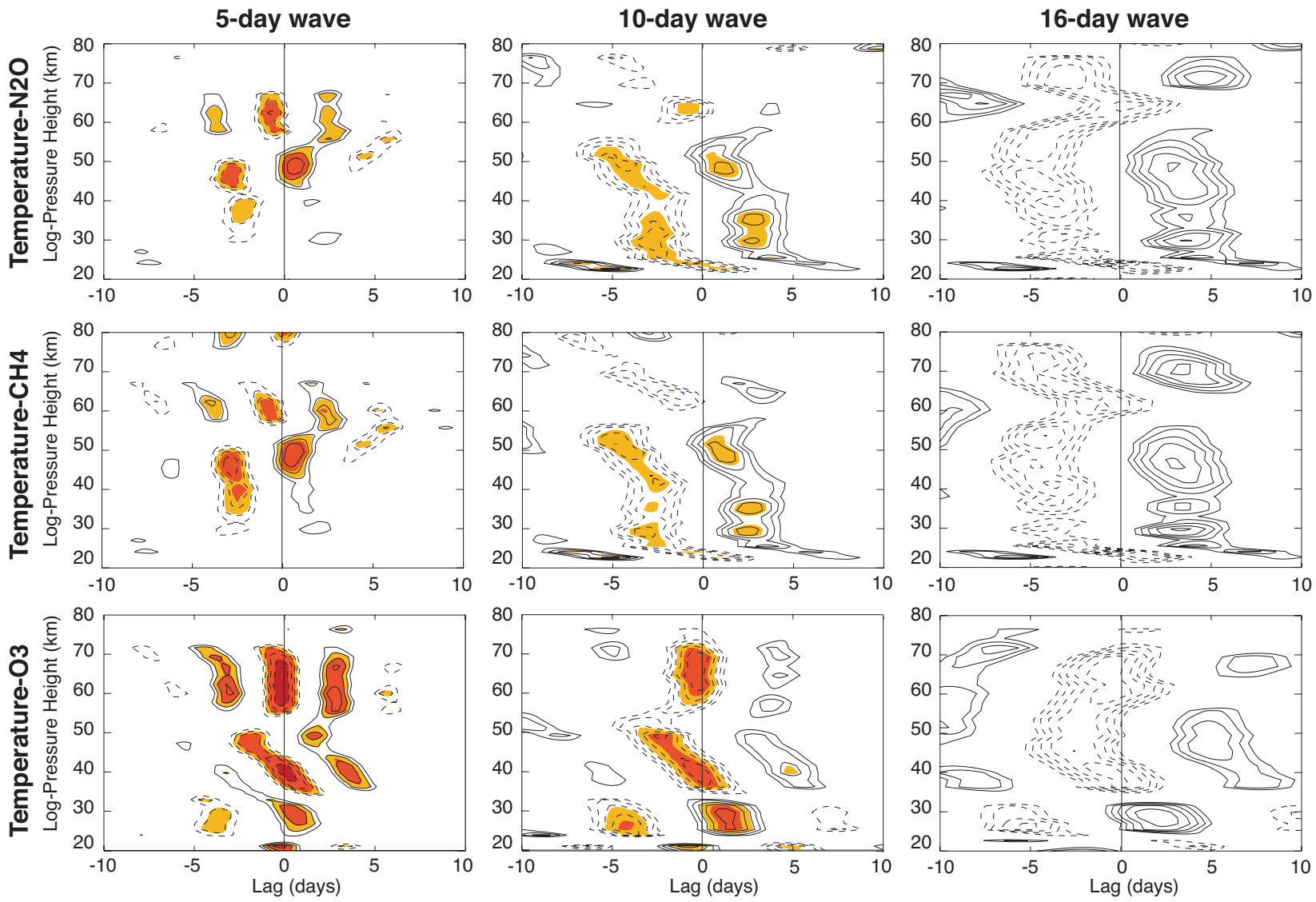

Fig. 7. Similar to Fig. 6 but for correlations between temperature- $\mathrm{N}_{2} \mathrm{O}$ (top row), temperature- $\mathrm{CH}_{4}$ (middle row) and temperature- $\mathrm{O}_{3}$ (bottom row) for the 5-day (left column), 10-day (middle column) and 16-day waves (right column).

\section{Interannual variability}

Although the 5-day, 10-day and 16-day waves are resonant modes of the atmosphere, all are expected to exhibit some interannual variability since the resonant properties of the atmosphere change with varying background winds and temperatures, which themselves exhibit interannual variability. In order to characterize the interannual variability of the waves, model data from 24 years of the global data set sampled at 18 hour intervals on five pressure levels for the months of August and September were used. Because of the coarser temporal sampling, the prominent diurnal cycle 

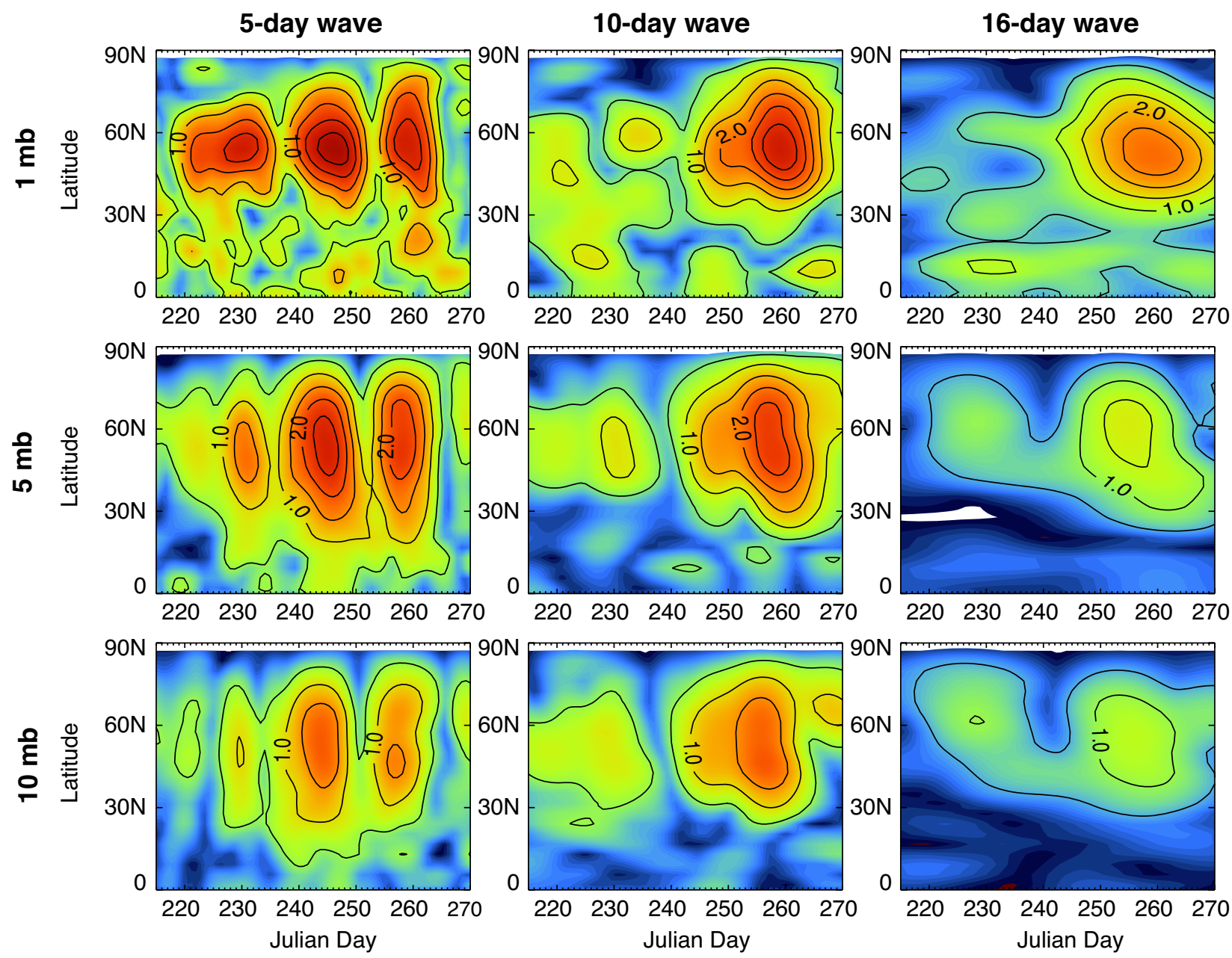

Fig. 8. Temperature amplitudes as calculated for Fig. 4, but for year 17 of the global data set. Amplitudes are shown for the NH only for the 5-day wave (left column), 10-day wave (middle column), and 16-day wave (right) column for pressure levels $1 \mathrm{mb}$ ( $\sim 48 \mathrm{~km})$ (top row), $5 \mathrm{mb}$ $(\sim 35 \mathrm{~km})$ (middle row) and $10 \mathrm{mb}(\sim 32 \mathrm{~km})$ (bottom row). Contour intervals are $0.5 \mathrm{~K} / \mathrm{km} / \mathrm{cpd}$ in all panels.

associated with the tide seen in the data set with higher temporal sampling was not as prominent, and no filtering was needed for the analysis. The Fourier-wavelet decomposition as described in Sect. 3 was used to isolate the waves, and amplitudes were again integrated over period ranges 4.6-6.5 days (5-day wave), 8.4-10.9 days (10-day wave) and 14.218.4 days (16-day wave). The ranges are slightly different than those used in the previous data set because of the different sampling interval, which produces different frequency intervals in the wavelet analysis. Only the highest altitudes are shown since the waves are harder to isolate on the 100 $\mathrm{mb}$ and $60 \mathrm{mb}$ pressure surfaces.

Results for a typical year are shown in Fig. 8. In this year, all three waves are present with approximately the same amplitudes, although the 10-day and 16-day waves develop later in the summer. For all years, the amplitudes are maximum near $50^{\circ} \mathrm{N}$, although the time evolution can be very differ- ent. The growth and decay of the waves, producing the lobed structure seen in the time evolution of the 5-day wave is common, although in some years the amplitudes decrease more rapidly in September. The later development of the 16-day wave is also common, although not universal. The 10-day wave shows greater variation in maximum amplitude.

To examine the year-to-year variability of the waves, the amplitudes were integrated over the latitude range $39^{\circ} \mathrm{N}$ to $72^{\circ} \mathrm{N}$. The results are shown in Fig. 9. Although the amplitude is never zero for any wave in any year, in some cases the amplitudes remain $<1 \mathrm{~K}$, and in other years one wave may dominate over the other two. For both the 10- and 16day waves, the amplitude tends to grow more steadily over the summer, whereas the 5-day wave amplitude shows the greatest variation in timing for reaching its maximum amplitude. That is, in some years the amplitude of the 5-day wave is largest in early August, in some it is largest in late 

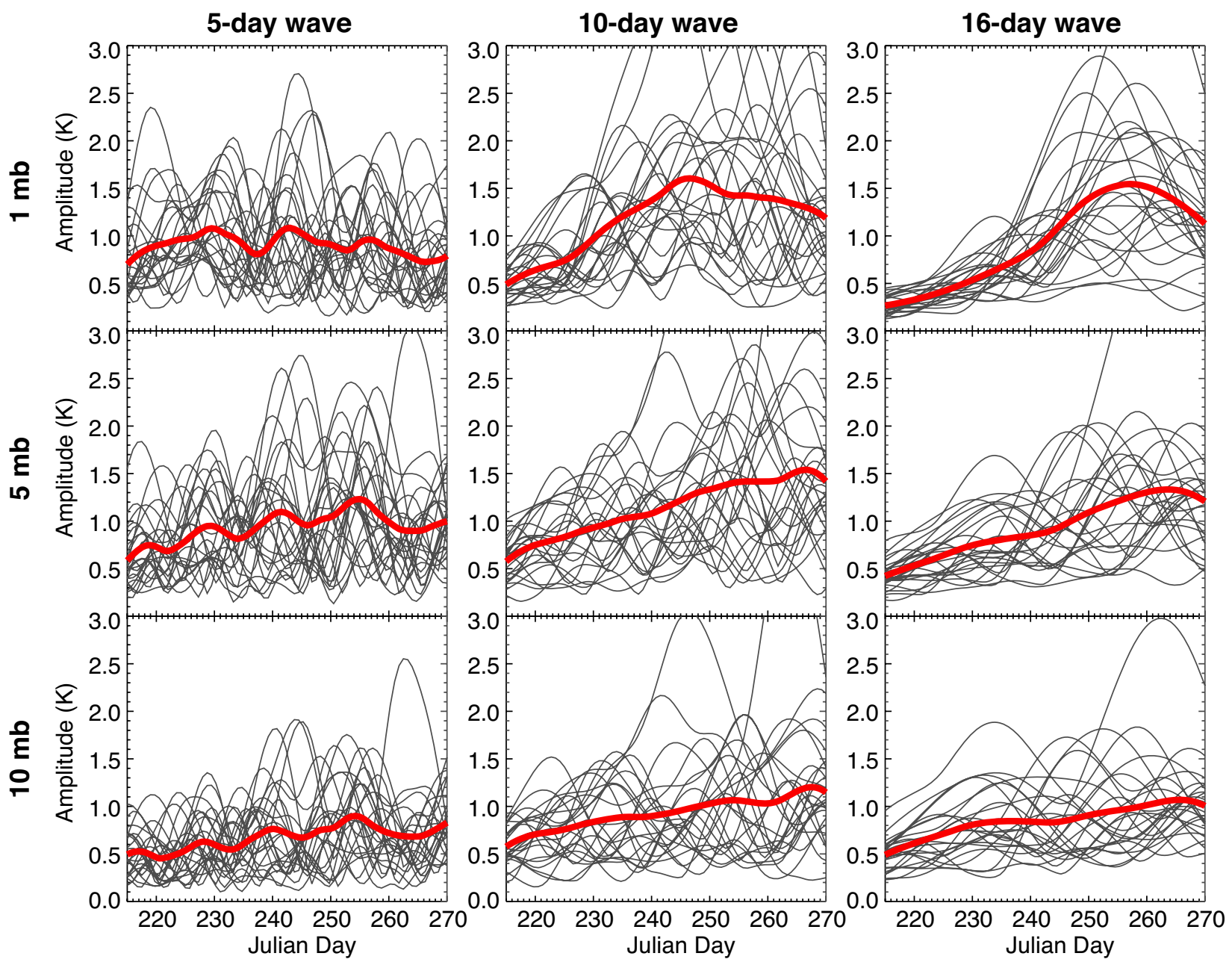

Fig. 9. Temperature amplitudes averaged over latitude for all 24 years from the global data set for the 5-day wave (left column), 10-day wave (middle column), and 16-day wave (right column) for pressure levels $1 \mathrm{mb}$ (top row), $5 \mathrm{mb}$ (middle row) and $10 \mathrm{mb}$ (bottom row). The 24-year average is indicated by the thick red line in each panel.

September, and in other years, the amplitude fluctuates over the entire period. For the 16-day wave, the amplitude starts relatively small in all years, and grows to a maximum amplitude later in the summer before eventually decaying. This is expected from the behaviour of the normal modes as calculated by Salby (1981). The 10-day wave has the largest amplitudes and the greatest variation in maximum amplitude. It tends to be strongest from late August to early September. As noted earlier, interpretation of the 10-day wave is difficult because of the overlap of periods between it and the 5- and 16-day waves.

\section{Discussion and Conclusions}

Using the CMAM, a fully-interactive coupled-chemistry climate model, the normal mode Rossby waves for the 5-, 10and 16-day waves in both the temperature and chemical fields have been analysed. All fields are shown to have 5-, 10- and 16- day waves. There is a clear correlation between the temperature, nitrous oxide, methane and ozone, both in physical space (considering all waves together) and when the correlations for each wave are considered separately. This gives us confidence in the physical relevance of these correlations. Yet the relationships are complicated and generally defy a simple explanation. Between $28 \mathrm{~km}$ and $33 \mathrm{~km}$, the temperature and chemical fields are well-correlated, with a lead of 2-3 days (Fig. 6).

The 5-day and 10-day waves in temperature and the chemical fields are well-correlated between $30 \mathrm{~km}$ and $60 \mathrm{~km}$, although here the correlations with ozone differ from those with nitrous oxide and methane. Because of the shorter lifetime of ozone at these altitudes, ozone most likely also responds directly to the 5- and 10-day waves in temperature. Indeed, there are zero-lag negative correlations between 
temperature and ozone around $40 \mathrm{~km}$ and $60 \mathrm{~km}$. While correlations exist between temperature and the chemical fields for the 16-day wave, they are not statistically significant due to the short duration of the wave and the limited time series.

The relationships between the waves in the dynamical and chemical fields are surprisingly complicated, even when the waves are considered individually, as in Fig. 7. For a longlived tracer advected purely by the meridional velocity $v$ of a given wave, a $90^{\circ}$ phase lag (e.g. 4 days for the 16-day wave) would be expected between $v$ and the tracer. The results here show some suggestion of this, but the phase relationships between $v$ and temperature, and temperature and the tracers vary in time and height, so it would seem that meridional transport is not the only active process. Advection of the chemical species by the vertical winds may play a role, but this hypothesis cannot be tested with the existing data set, since no information pertaining to the meridional structure is available.

This modelling study suggests that the variability in chemical constituents induced by normal mode Rossby waves in the summer stratosphere should be taken into account when estimating long-term trends from the MANTRA campaigns, since measurements are made for only one day at a time. Our examination of the interannual variability of the 5-, 10- and 16- day waves shows that these waves could, and likely do, exist during the MANTRA campaigns in August and September. However, further information is required to quantify the effects. Which waves are most likely present would depend to some extent on the timing of the launch launches later in the summer are more likely to see longer period waves - and on the particular year. Ground-based measurements or temperature analyses supporting the balloon measurements may be necessary to provide the phase and amplitude of the waves during the balloon launch. Analysed meteorological fields could also provide the meridional structure of the waves, and more clearly identify which modes are present.

Further study with a global data at finer temporal sampling would be useful for several reasons. First, the choice of frequency separation between the 5-, 10- and 16- day waves in this study was somewhat arbitrary, based only on the frequency variations calculated by Salby (1981). This is not ideal since, as seen in Fig. 3, the 5-day wave in the CMAM is skewed towards longer periods in the allowable frequency range. In addition, the frequency range for the 16-day wave can overlap that of the 10-day wave making it difficult to properly distinguish between the two. Since all three of the wavenumber 1 normal modes have maximum amplitudes near $50^{\circ} \mathrm{N}$, their distinct meridional phase structures are the only way to truly distinguish between them. With only one latitude in the data set with the high temporal sampling, it is impossible to determine the meridional structure of the waves, which can help to identify the normal modes. In the case of the global data, the temporal and vertical resolution of the data is insufficient to obtain definitive phase structures, and the temporal sampling of the chemical species (every three days) was insufficient to test the interannual variability of the correlations.

In the future, climate analyses could be used for a similar study, however certain conditions would have to be met. The analysis would have to extend high enough in the vertical, although as more and more analyses are being extended vertically, this becomes less of a limitation. In addition, the analyses would have to include online chemistry, or at the very least chemical species advected by meteorological winds with temperature dependence for chemistry. Climate analyses that include the assimilation of chemical fields would not be suitable since the relationship between the chemistry and the transport would be affected by the data assimilation process. Rather, these sorts of diagnostics would be useful to validate the chemical-dynamical relationships produced by simultaneous chemical-dynamical data assimilation.

Acknowledgements. The authors would like to thank S. Melo and D. Sankey for initial discussions. Publication of this work was supported by the Canadian Foundation for Climate and Atmospheric Sciences.

Edited by: A. Richter

\section{References}

Austin, J., Shindell, D., Brühl, C., Dameris, M., Manzini, E., Nagashima, T., Newman, P., Pawson, S., Pitari, G., Rozanov, E., C. Schnadt, C., and Shepherd, T. G.: Uncertainties and assessments of chemistry-climate models of the stratosphere, Atmos. Chem. Phys., 3, 1-27, 2003, http://www.atmos-chem-phys.net/3/1/2003/.

Beagley, S. R., de Grandprè, J., Koshyk, J. N., McFarlane, N. A., and Shepherd, T. G.: Radiative-dynamical climatology of the first-generation Canadian Middle Atmosphere Model, Atmos.Ocean, 35, 293-331, 1997.

Cheong, H.-B. and Kimura, R.: Excitation of the 5-day wave by Antarctica, J. Atmos. Sci., 54, 87-102, 1997.

Cheong, H.-B. and Kimura, R.: Excitation of the 10-day and 14-day waves, J. Atmos. Sci., 58, 1129-1145, 2001.

de Grandprè, J., Beagley, S. R., Fomichev, V. I., Griffioen, E., McConnell, J. C., Medvedev, A. S., and Shepherd, T. G.: Ozone climatology using interactive chemistry: Results from the Canadian Middle Atmosphere Model, J. Geophys. Res., 105, $26475-$ 26491, 2000.

Geisler, J. E. and Dickinson, R. E.: The five-day wave on a sphere with realistic zonal winds, J. Atmos. Sci., 33, 632-641, 1976.

Hines, C. O.: Doppler-spread parameterization of gravity-wave momentum deposition in the middle atmosphere. Part 1: Basic formulation, J. Atmos. and Solar-Terr. Phys., 59, 371-386, 1997.

Hirooka, T.: Normal mode Rossby waves as revealed by UARS/IASMS observations, J. Atmos. Sci., 57, 1277-1285, 2000.

Hirooka, T. and Hirota, I.: Further evidence of normal mode Rossby waves, Pageoph., 130, 277-289, 1989. 
Hirota, I. and Hirooka, T.: Normal mode Rossby waves observed in the upper stratosphere. Part I: First symmetric modes of zonal wavenumbers 1 and 2, J. Atmos. Sci., 41, 1253-1267, 1983.

Madden, R. A.: Further Evidence of Traveling Planetary Waves, J. Atmos. Sci., 35, 1605-1618, 1978.

Madden, R. and Julian, P.: Further evidence of global-scale, 5-day pressure waves, J. Atmos. Sci., 29, 1464-1469, 1972.

McLandress, C.: Seasonal variability of the diurnal tide: Results from the Canadian middle atmosphere general circulation model, J. Geophys. Res., 102, 29,747-29,764, 1997.

McLandress, C.: On the importance of gravity waves in the middle atmosphere and their parameterization in general circulation models, J. Atmos. Sol.- Terr. Phys., 60, 1357-1383, 1998.

Miyoshi, Y.: Numerical simulation of the 5-day and 16-day waves in the mesopause region, Earth Planets Space, 51, 763-772, 1999.
Miyoshi, Y. and Hirooka, T.: A numerical experiment of excitation of the 5-day wave by a GCM, J. Atmos. Sci., 56, 1698-1707, 1999.

Prata, A. J.: Observations of the 5-day wave in the stratosphere and mesosphere, J. Atmos. Sci., 46, 2473-2477, 1989.

Salby, M. L.: Rossby normal modes in nonuniform background configurations. Part II: Equinox and solstice conditions, J. Atmos. Sci., 38, 1827-1840, 1981.

Sankey, D. and Shepherd, T. G.: Correlations of long-lived chemical species in a middle atmosphere general circulation model, J. Geophys. Res., 108, 10.1029/2002JD002 799, 2003.

Sciremammano, F., Jr.: A suggestion for the presentation of correlations and their significance levels, J. Phys. Ocean., 9, 1273-1276, 1979. 